\title{
Canadian Committee on Antibiotic Resistance report
}

\author{
John M Conly MD FRCPC 1 , Scott McEwen DVM DVSc Diplomate ACVP2 ${ }^{2}$, Jim Hutchinson MD FRCPC ${ }^{3}$, \\ Nora Boyd RN MEd CIC ${ }^{4}$, Sandra Callery RN MHSc CIC ${ }^{5}$, Elizabeth Bryce MD FRCPC 6
}

$\mathrm{T}_{\mathrm{c}}^{\mathrm{h}}$ he present article, one in a series of articles provided by the Canadian Committee on Antibiotic Resistance (CCAR), is intended to update readers on current activities focused on limiting the development and transmission of resistance in Canada. Headquartered in Vancouver, British Columbia, the CCAR provides outreach to public and professional communities through a variety of activities focused on infection prevention and control, resistance surveillance and optimal antibiotic use.

At the Conjoint Conference of the Canadian Infectious Diseases Society (now the Association of Medical Microbiology and Infectious Disease Canada) and the Community and Hospital Infection Control Association of Canada, CCAR assisted in the development of a symposium on antibiotic resistance (May 2, 2004, Calgary, Alberta). This forum was used to introduce CCAR's Proposed National Action Plan to Address Antibiotic Resistance. Comments on the Plan are now being solicited before its public release targeted for October 2004. The Plan is available on the CCAR Web site (1) at $<$ http://www.ccar-ccra.com/pdf/Action\%20Plan.Sept2004.pdf>.

The symposium was attended by over 200 delegates of the Conjoint Conference. Summarized below are four of the key presentations which formed the majority of the symposium's content.

\section{REPORT CARD ON AGRICULTURE}

\section{Dr Scott McEwen}

The link between agricultural use and human health is a central issue for the use of antibiotics in agriculture. Other important issues include prudent use practices and surveillance. There are a number of public health impacts related to antibiotic resistance that are both potential and real.

- There is the possibility that drugs may no longer be useful when treating humans.

- There can be increased risk of new infection with resistant strains when taking antimicrobials for other health reasons. Individuals can lose their natural ability to fight infection because enteric microflora capable of fighting these low-level infections are affected by antibiotics.

- The severity of infections may be increased. For example, people infected with Salmonella typhimurium show signs of increased morbidity and mortality. Potentially, the antimicrobial disruption of normal enteric flora may increase the risk of infection and spread of resistant pathogens in animals, which could then increase the flow of pathogens to humans.

- Resistant genes could build up in animal populations. These resistant genes, which can occur in genetically linked arrays, could potentially be accessed by human pathogens. This highlights the issue of antimicrobial

resistance as an ecological problem that could cross species

barriers and ecosystems.

These issues point to the need to improve surveillance of both resistance and antibiotic use. A new program, the Canadian Integrated Program for Antimicrobial Resistance Surveillance, is attempting to address this need. The Canadian Integrated Program for Antimicrobial Resistance Surveillance conducts laboratory analysis in three locations. Their 2002 annual report is now available at <www.hc-sc.gc.ca/pphb-dgspsp /cipars-picra/index.html> (2).

Active surveillance of abattoirs was one of the key areas of this report. Beef cattle, broiler chickens and swine were analyzed at 51 abattoirs. The results showed salmonella resistance to one or more antimicrobials at levels of $45 \%$ to $48 \%$ for both chicken and swine. Escherichia coli resistance was even higher in these two species (resistance levels of $80 \%$ for both). Cattle only showed resistance to E coli at levels of $31 \%$. When analysis of resistance to five or more antimicrobials was conducted on these animals, only chicken and swine showed salmonella resistance levels of $12 \%$ and $20 \%$, respectively, and E coli resistance levels of $33 \%$ and $11 \%$, respectively. Unfortunately, there were too few isolates available from cattle for analysis.

Surveillance of retail food in chain stores, independent stores and specialty stores began in May 2003. In addition to this activity, pilot projects for monitoring antibiotic use were also initiated in 2003.

Concerns exist with respect to aquaculture, particularly in Southeast Asia where antibiotics are intensively used. In North America, one factor that mitigates against natural selection is that lower amounts of enteropathogens exist (eg, Salmonella) in the gastrointestinal tracts and environment of colder water fish. There is also a limited range of antimicrobials that are available for aquaculture use in North America.

While significant progress has been made in Canada and internationally, much still remains to be done. Key areas of focus include the conduct of appropriate research and the improvement of surveillance and risk assessment. In particular, prudent use principles at the farm level need to be implemented.

\section{REPORT CARD ON HUMAN HEALTH Dr John Conly}

Antibiotic resistance is one of the most serious global threats to the treatment of infectious diseases (3-9). Antibiotic-resistant organisms erode our therapeutic inventory and cause significant increases in the cost and toxicity of newer drugs. Antibiotic resistance is, at its core, an ecological issue. This is illustrated by the recognition that its impact will be felt on a variety of levels: human, animal health, agriculture and environment.

${ }^{1}$ Departments of Pathology and Laboratory Medicine, Medicine, and Microbiology and Infectious Diseases, Centre for Antimicrobial Resistance, University of Calgary, Calgary, Alberta; ${ }^{2}$ Ontario Veterinary College, University of Guelph, Guelph, Ontario; ${ }^{3}$ Health Sciences Centre, St John's, Newfoundland; ${ }^{4}$ Bluewater Health, Sarnia, Ontario; ${ }^{5}$ St Joseph's Hospital, Hamilton, Ontario; ${ }^{6}$ Vancouver General Hospital, Vancouver, British Columbia

Correspondence and reprints: Rick Walter, Canadian Committee on Antibiotic Resistance, 3806 West 33 Avenue, Vancouver, British Columbia V6N 2H6. Telephone 604-263-4520, fax 604-263-7074,e-mail ccar@shaw.ca 
Antimicrobial stewardship and infection prevention and control practices (including environmental hygiene) play an important role in limiting the transmission of antimicrobial-resistant organisms in all health care settings. These practices are key in controlling antimicrobial resistance and achieving an ecological balance between susceptible and resistant microbes in humans $(10,11)$.

In addition to stewardship and infection prevention and control, surveillance of resistant strains in both hospital and community settings provides key information for effective management of patient care and prescription practices. From the human health perspective, tracking of antibiotic resistance in selected areas has been conducted through surveillance network activity at the national, provincial and regional levels.

The Canadian Nosocomial Infection Surveillance Program (CNISP), established in 1994, is one such network. The CNISP is a national and collaborative program between Health Canada and the Canadian Hospital Epidemiology Committee (a subcommittee of the Association of Medical Microbiology and Infectious Disease Canada) that has accumulated data since 1995 on the incidence of selected hospital-acquired antibiotic-resistant organisms. In general, while Canadian resistance rates are substantially lower than those found in the United States (US) (12), they are still higher than those experienced in Denmark and other developed nations. Approximately 50\% of the Staphylococcus aureus isolates from hospitals in the US are methicillin-resistant strains; this figure appears to be increasing. Canada has experienced an increase in the percentage of $S$ aureus isolates reported as methicillin-resistant from hospitals, but recent data from CNISP reveal that the proportion of $S$ aureus isolates (representing both colonization and infection) reported as being methicillin-resistant increased from 1.0/100 isolates (0.5/1000 admissions) in 1995 to 10/100 isolates (5.4/1000 admissions) in 2003 (Health Canada, unpublished data). Vancomycin-resistant enterococci (VRE), as a percentage of all nosocomial enterococcal infections, are increasing in the US at a rate of approximately $2.5 \%$ per year to their current level of approximately 25\% (12). In contrast, Canada has experienced no increases with respect to VRE in a similar setting, with rates less than $0.1 \%$. Data collected for community antibiotic-resistant organisms focus predominantly on Streptococcus pneumoniae. The percentage of penicillinresistant $S$ pneumoniae within Canadian jurisdictions varies according to data collection methods and whether invasive or noninvasive strains are used. The prevalence of clinical isolates with reduced susceptibility to penicillin (both intermediatelevel and high-level resistance) from respiratory tract sites increased from less than $2 \%$ in the late 1980 s to $21 \%$ in 2003 (13), with up to $7 \%$ of isolates having high-level resistance according to one surveillance system. Another surveillance system examining only invasive pneumococcal infections was conducted by 11 pediatric centres from the Canadian Paediatric Society/Laboratory Centre for Disease Control Immunization Monitoring Program, Active (IMPACT), found an overall rate of penicillin resistance of $6.8 \%$ between the years 1991 to 1998 for penicillin-resistant S pneumoniae $(5.1 \%$ intermediate-level and $1.7 \%$ high-level resistance to penicillin) (14). The international situation is more dramatic. The percentages in the US for resistant strains continue to rise beyond 2001 levels of $42 \%$ to $44 \%$ (12). In Asian countries, such as Taiwan, Vietnam and Hong Kong, these rates range from $70 \%$ to $90 \%$ (12).

A number of hurdles still exists within the surveillance field, including the fragmented nature and relatively slow access to collated hospital data. As well, no national population-based sur- veillance activity for community-acquired pathogens exists. The surveillance of antimicrobial-resistant pathogens in water and food supplies is less than optimal, and research needs to be conducted to determine the best modes for surveillance and mechanisms of resistance in both animals and humans.

Data from 1997 to 2002 show a reduction in the use of certain antibiotics (15). Specifically, tetracycline and cephalosporin use is declining. Total beta-lactam prescriptions decreased by $20.8 \%$ during the same period (12).

The CCAR has spent an active year in communications and outreach, policy development and promoting/facilitating the judicious use of antibiotics. In addition, a study on the economic burden of illness stressed that increased rates of antibiotic resistance in Canadian hospitals (similar to levels in the US) would result in a very significant impact to the overall health care system (16). For example, the use of newer, more potent and expensive drugs could increase costs to as much as $\$ 1.8$ billion from the current estimated $\$ 600$ million spent on oral antibiotics.

In terms of future activities, the National Action Plan and a projected national labelling initiative will be key focus areas for the CCAR in 2004. Other priorities include continued communications and policy efforts (as outlined on the CCAR Web site).

\section{ANTIBIOTIC USE - ANALYSIS AND INTERVENTIONS - HOW MUCH IS GOOD?}

\section{Dr Jim Hutchinson}

In general, although annual antibiotic prescriptions have decreased in Canada, fluoroquinolone prescriptions have increased. However, noticeable time-limited decreases have occurred in Prince Edward Island, Newfoundland, New Brunswick and Ontario. These decreases have been coincident with specific interventions, the most effective of which was administrative controls over payment for fluoroquinolones. Changes to a 'Limited Use Listing' status in Ontario and 'Special Authorization Listing' in New Brunswick were associated with significant reductions in prescriptions.

To suitably manage antibiotic utilization, proper measurement of consumption is required. We should work hard to optimize levels and types of antibiotic consumption, and then live with the resultant levels of resistance. The determination of optimal levels of antibiotic consumption is the key to attaining these levels.

When introducing new antibiotics, it is important to predetermine a desired level of consumption that maximizes benefit while minimizing the development of resistance using a well-thought-out plan. Such an initiative requires a rational, step-by-step approach when determining these desired levels. These steps include:

- Defining the incidence of disease(s) for which the new antibiotic is indicated;

- Defining the proportion of expected or desired use;

- Defining timelines (rates of increase);

- Measuring consumption;

- Predefining threshold levels of consumption at which intervention is deemed appropriate; and

- Predefining the interventions that are triggered when consumption has increased undesirably.

This approach could enhance interactions between all parties with an interest in antibiotic utilization and could foster a thoughtful, careful environment.

Antibiotics are far too important to be distributed by existing market forces. Although many types of interventions have 
been used (eg, education programs for physicians, pharmacists and consumers; posters and pamphlets; and guidelines), administrative interventions are the most effective by far. The range of potential administrative interventions is considerable and includes formularies, autosubstitution and various forms of restricted access. Administrative controls have been used to good effect for many years in hospitals and they should be broadened to all provincial formularies to guide antibiotic use and ensure that Canadians have continued access to important antibiotics for disease management.

\section{EXTENDED-SPECTRUM BETA-LACTAMASE PATIENT ISOLATION DEBATE}

\section{Nora Boyd (moderator), Sandra Callery} and Elizabeth Bryce

The purpose of the present discussion was to debate the validity of various infection prevention and control approaches when dealing with extended-spectrum beta-lactamase-producing organisms (ESBLs). In the first role play of the 'debate', Elizabeth Bryce emphasized that the use of barriers (as described in routine practices with the emphasis on hand hygiene for direct contact) is the most important component for controlling the spread of ESBLs in nonoutbreak situations. Her 'opponent', Sandra Callery, presented the position that selective screening and contact precautions using a single room or cohorting is critical to controlling the spread of ESBLs. Nora Boyd moderated the debate. The opposing positions are described below.

\section{Elizabeth Bryce}

ESBLs are transmitted either through clonal dissemination of strains or polyclonal dissemination where plasmids carrying the ESBL gene are transmitted to other Enterobacteriaceae species. In Canada, the prevalence rate in the majority of hospitals is low, and a broad range of ESBLs are present, indicating unrelated spontaneous mutations versus patient-to-patient transmission. To date, clonal distribution has been observed at some sites, but there appears to be limited intrahospital spread.

Typical infection control precautions for antibiotic-resistant organisms include contact precautions, reinforcement of hand hygiene and education. Isolating patients may be effective in some instances (eg, outbreaks) but should not be considered a standard means for infection control and intervention with this organism because it is expensive, time consuming and can negatively impact patients and their families.

Although some believe that isolation is appropriate for ESBLs, isolating individuals with ESBLs that have been identified from clinical specimens would address only the 'tip of the iceberg' and would fail to identify asymptomatic carriers. To be truly effective, the majority of individuals with ESBLs would have to be identified to limit transmission. This leads to the issue of screening. A screening program for ESBLs would be very expensive. Compared with methicillin-resistant $S$ aureus (MRSA), at my institution alone (Vancouver Hospital and Health Sciences Centre, British Columbia), the cost of screening specimens just for ESBL Klebsiella and E coli would range from $\$ 140,000$ to $\$ 200,000$. The screening program would not address the issue of spread to other Enterobacteriaceae. And with no evidence of an outbreak, this expense could not be justified.

Most of the evidence regarding control of ESBLs emphasizes the importance of consistent application of routine practices and hand hygiene. Investing our time and money in appropriate education and training would address not only ESBLs, but also other hospital-acquired organisms. Ultimately, consumption of antibiotics should be decreased and the use of barriers maximized. Antibiotic resistance will always be with us - we must learn to manage it effectively without undue consumption of our precious resources.

\section{Sandra Callery}

It has been argued that contact precautions using single rooms and cohorting ESBL-positive patients play an important part in controlling ESBLs, particularly in outbreak situations. There is a very real risk that ESBLs will become our next MRSA problem. In part, this is exacerbated by the fact that routine practices may not be so 'routine'. Health care providers are carrying out patient care at a hectic pace and compliance with routine practice is inconsistent at best. More aggressive measures include surveillance for colonization, the use of barriers, contact precautions using single rooms and cohorting, education, hand washing and monitoring for compliance. A number of cases where aggressive infection control measures were successful in terminating the outbreak have been highlighted. Such cases included one from Chicago (17) and another from France (18). In both cases, the rates of the virulent organisms in question decreased dramatically. The takehome lesson here is that ESBL infection control can be properly managed using the following strategies: patient hygiene (not just hands); contact precautions; single rooms or cohort; enhanced environmental cleaning; review of staff multitasking; acting on symptoms of diarrhea; and restricting the use of communal toilet facilities. The use of single rooms and cohorting does not need to have the degree of negative impact described. The impact on patients can be reduced through a variety of means, including education, allowing for patient interaction, physical therapy, mental stimulation and empowerment.

\section{Wrap up}

At the end of the day, both of these perspectives can be better integrated to address both outbreak and nonoutbreak scenarios. The happy medium between the above viewpoints would include continued emphasis on routine practices, attention to the environment and facility design, maintenance of high levels of hand hygiene and increased resources for long-term care. Other areas that require attention include antibiotic prescribing practices, focused surveillance, appropriate intervention and improved communication.

\section{OTHER ACTIVITIES RELATED TO ANTIBIOTIC RESISTANCE}

\section{National}

The CNISP continues to conduct surveillance for antimicrobialresistant organisms in 37 sentinel hospitals across the country. Target organisms include MRSA, VRE and ESBLs such as E coli and Klebsiella species.

In 2003, the last year for which surveillance data are available, MRSA rates continued to rise, with an overall national rate of 5.4 per 1000 admissions and 10.0 per $100 \mathrm{~S}$ aureus isolates (compared with 8.4 per 1000 admissions and 4.3 per $100 \mathrm{~S}$ aureus isolates in 2002). MRSA infection rates were also higher in 2003 ( 1.2 per 1000 admissions) than in 2002 (0.9 per 1000 admissions). The highest rates of MRSA were reported from participating hospitals in Quebec, Ontario and British Columbia. Most MRSA infections in Canadian hospitalized patients were acquired nosocomially, athough approximately $9 \%$ were thought to have been community-acquired. A study 
to determine the outcome of invasive MRSA infections in Canadian hospitals is currently being done, and a report describing the epidemiology of MRSA in Canadian aboriginal people has been submitted for publication.

Between 1998 and 2002, the rate of VRE in CNISP hospitals has increased slightly to 0.5 per 1000 admissions and $0.2 \%$ of enterococcal isolates. In comparison, National Nosocomial Infections Surveillance data from the United States indicate VRE rates of approximately $12 \%$ among inpatients. A CNISP survey recommends that participating hospitals use admission screening policies for early detection of VRE, and that barrier precautions are used for identified patients. A paper presented by CNISP at the 2004 Annual Meeting of the Society for Healthcare Epidemiology of America suggested that these measures may contribute to the low incidence of VRE in Canadian hospitals (19).

An ongoing study is aimed at determining risk factors for the acquisition of ESBLs and characterizing these strains.

\section{Regionally}

A number of activities currently underway in regions across Canada have been listed in the Proposed National Action Plan (1). Since this report became available, new activities have been initiated in both British Columbia and the Northwest Territories. These activities are highlighted.

British Columbia: British Columbians use more antibiotics than northern Europeans. This could create a problem because the overuse of antibiotics contributes to the emergence of antibiotic-resistant microorganisms according to a study by

\section{REFERENCES}

1. Canadian Committee on Antibiotic Resistance. <http://www.ccarccra.com/pdf/Action\%20Plan.Sept2004.pdf> (Version current at September 29, 2004).

2. Canadian Integrated Program for Antimicrobial Resistance Surveillance. <http://www.hc-sc.gc.ca/pphb-dgspsp/ciparspicra/index.html> (Version current at September 9, 2004).

3. World Health Organization: Overcoming antimicrobial resistance. Report on infectious diseases 2000. <www.who.int/infectious-diseasereport/2000/index.html > (Version current at September 9, 2004).

4. American Society for Microbiology. Report of the ASM task force on antimicrobial resistance. Antimicrob Agents Chemother 1995;(Suppl):1-23.

5. Goldmann DA, Weinstein RA, Wenzel RP, et al. Strategies to prevent and control the emergence and spread of antimicrobialresistant microorganisms in hospitals. A challenge to hospital leadership. JAMA 1996;275:234-40.

6. Swartz MN. Use of antimicrobial agents and drug resistance. N Engl J Med 1997;337:491-2.

7. Kunin CM. Resistance to antimicrobial drugs - a worldwide calamity. Ann Intern Med 1993;118:557-61.

8. Centers for Disease Control and Prevention. Addressing emerging infectious disease threats: A prevention strategy for the United States. Executive summary. MMWR Recomm Rep 1994:43:1-18.

9. Central Intelligence Agency. The global infectious disease threat and its implications for the United States.

<http://www.odci.gov/cia/reports/nie/report/nie99-17d.html> (Version current at September 9, 2004).

10. Moberg CL. Rene Dubos: A harbinger of microbial resistance to antibiotics. Microb Drug Resist 1996;2:287-97.

11. Levy SB. Antibiotic resistance: An ecological imbalance. Ciba Found Symp 1997;207:1-14.

12. Conly J. Antimicrobial resistance in Canada. CMAJ 2002;167:885-91.

13. Palatnick B, Weshnoweski B, Bellyou T, Topnik D, Zhanel GG, researchers at the University of British Columbia. The study, which appeared in the July 1, 2004 issue of Clinical Infectious Diseases, is available online (20).

The study measured antibiotics dispensed in British Columbia and several European countries, making specific usage comparisons between British Columbia and Denmark. Common microorganisms that cause respiratory and urinary tract infections are shown to be developing increased resistance to antibiotics. The unnecessary use of these antimicrobials only increases the mounting resistance of microorganisms.

As well, the Alberta-based "Do Bugs Need Drugs?" program is expanding its work into British Columbia with project funding from Health Canada's Best Practices Program. The project will suitably translate and distribute knowledge and awareness surveys to Chinese-speaking parents presenting at Vancouver-based public health clinics for child immunizations and through Chinese language elementary schools. The project will also provide traditional and simplified Chinese versions of the "Do Bugs Need Drugs?" parent guide to the target population.

Northwest Territories: Dr Marie Claude Lebeau has led the development and implementation of a program in the Northwest Territories. A new Antimicrobial Steering Committee created posters, bookmarks, brochures, hand washing stickers and large hand washing posters designed to adhere to bathroom stall doors. Hand washing demonstrations were also provided. For health care professionals, prescription pads and Clinical Practice Guidelines were distributed, and infection control standards for hospitals and health centres were developed.

Hoban D. Evaluation of antibiotic susceptibility in 17,585 respiratory tract infection pathogens collected across Canada from 1997-2002: Results of the Canadian respiratory organism susceptibility study (CROSS). The 43rd Interscience Conference on Antimicrobial Agents and Chemotherapy. Chicago, September 2003:E-2184. (Abst)

14. Scheifele D, Halperin S, Pelletier L, Talbot J. Invasive pneumococcal infections in Canadian children, 1991-1998: Implications for new vaccination strategies. Canadian Paediatric Society/Laboratory Centre for Disease Control Immunization Monitoring Program, Active (IMPACT). Clin Infect Dis 2000;31:58-64.

15. IMS HEALTH Canada and Canadian Committee on Antibiotic Resistance. Antibiotic use data by region and by product class from 1996 to December 2000. <http://www.ccar-ccra.com/optimal-e.htm> (Version current at September 9, 2004).

16. Birnbaum D. Canadian Committee on Antibiotic Resistance. Antimicrobial resistance: A deadly burden no country can afford to ignore. Can Commun Dis Rep 2003;29:157-64.

17. Wiener J, Quinn JP, Bradford PA, et al. Multiple antibiotic-resistant Klebsiella and Escherichia coli in nursing homes. JAMA 1999;281:517-23.

18. Lucet JC, Decre D, Fichelle A, et al. Control of a prolonged outbreak of extended-spectrum beta-lactamase-producing enterobacteriaceae in a university hospital. Clin Infect Dis 1999;29:1411-8.

19. Johnston L, Ofner-Agostini M, Conly J, et al. Infection control strategies to prevent the transmission of vancomycin-resistant enterococci (VRE) in hospitals participating in the Canadian Nosocomial Infection Surveillance Program. 14th Annual Scientific Meeting, Society for Healthcare Epidemiology of America. Philadelphia, April 17-20, 2004:337 (Abst).

20. Per capita antibiotic consumption: How does a North American jurisdiction compare with Europe? $<$ http://www.journals.uchi cago.edu/CID/journal/issues/v39n1/32888/brief/32888.abstract.html> (Version current at September 29, 2004)

CCAR members include a variety of human health care and agricultural professional organizations, not-for-profit associations and government agencies. CCAR activities are funded primarily through a contract agreement with Health Canada and administered through the AMMI. As well, project funding is raised, in part, through educational grants from several companies with an interest in antibiotic resistance.

For more information about CCAR, please contact Rick Walter, Executive Director, 3806 West 33 Avenue, Vancouver, British Columbia V6N 2H6. Telephone 604-263-4520, fax 604-263-7074, e-mail ccar@shaw.ca, Web site www.ccar-ccra.org. 


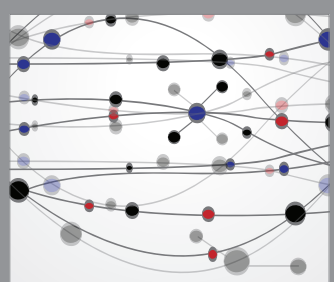

The Scientific World Journal
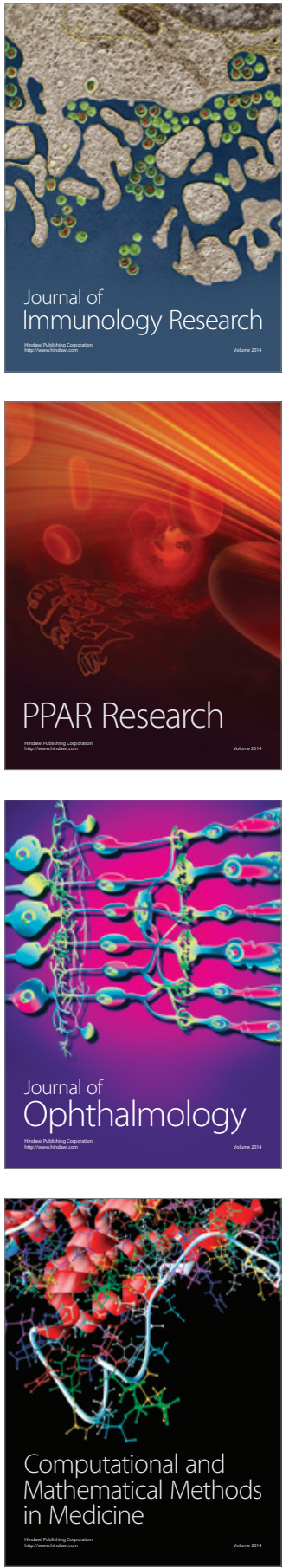

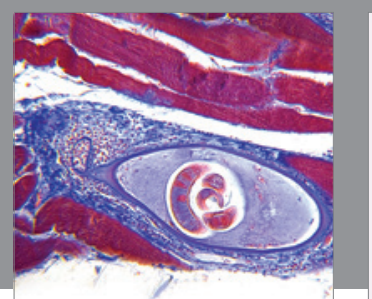

Gastroenterology Research and Practice

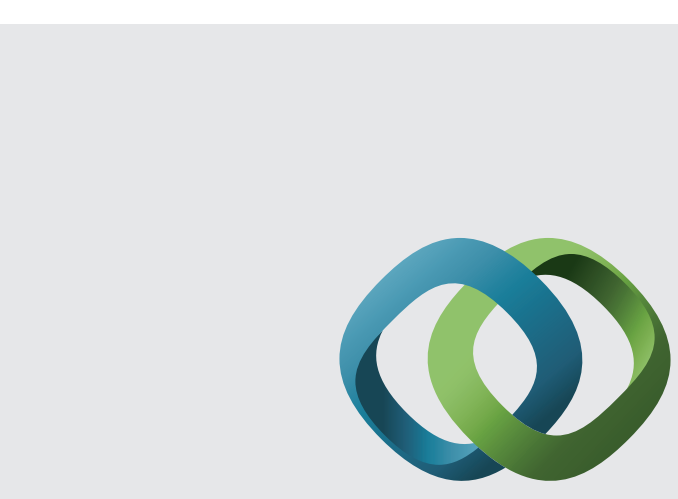

\section{Hindawi}

Submit your manuscripts at

http://www.hindawi.com
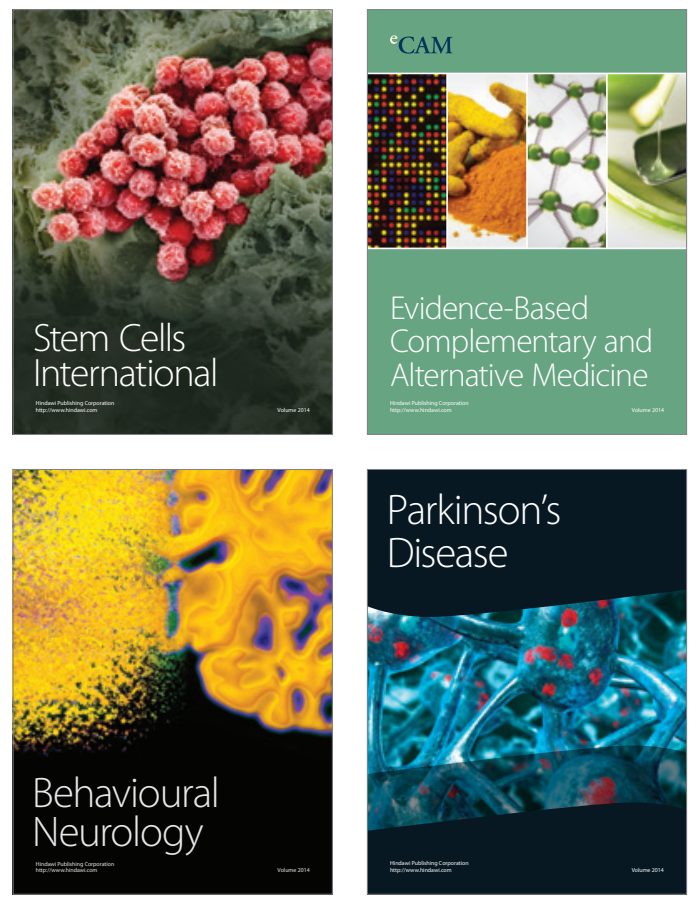
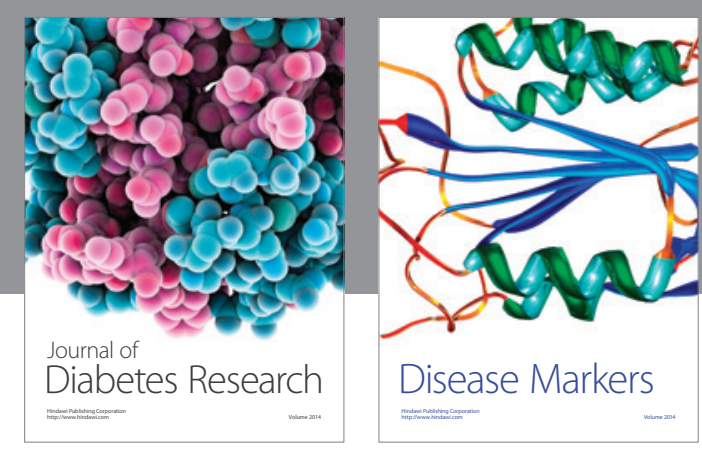

Disease Markers
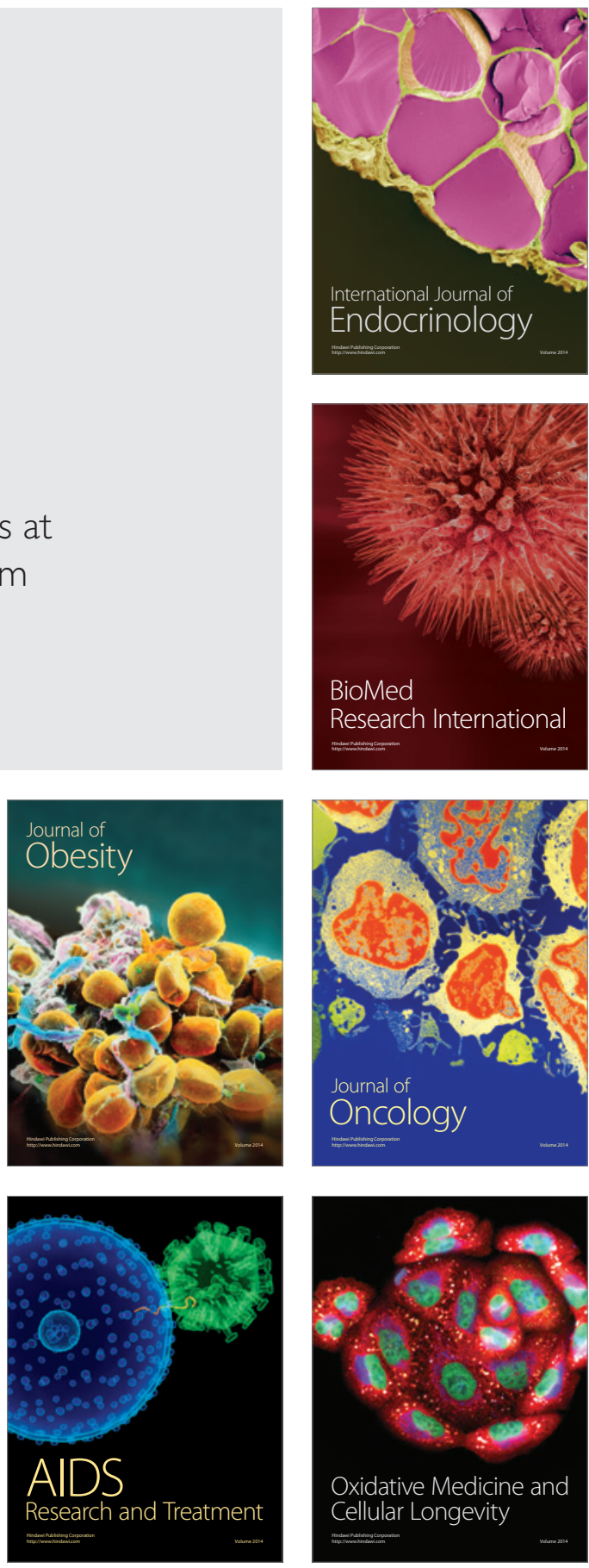